Lada Hanzelinova, 2019

Volume 5 Issue 1, pp. 217-227

Date of Publication: 28 ${ }^{\text {th }}$ March 2019

DOI-https://dx.doi.org/10.20319/pijss.2019.51.217227

This paper can be cited as: Hanzelinova, L., (2019). Czech Academic Etiquette. PEOPLE: International Journal of Social Sciences, 5(1), 217-227.

This work is licensed under the Creative Commons Attribution-Non Commercial 4.0 International License. To view a copy of this license, visit http://creativecommons.org/licenses/by-nc/4.0/ or send a letter to Creative Commons, PO Box 1866, Mountain View, CA 94042, USA.

\title{
CZECH ACADEMIC ETIQUETTE
}

\author{
Lada Hanzelinova \\ Department of Philosophy, Faculty of Art, University of West Bohemia, Czech Republic \\ ladahan@kfi.zcu.cz
}

\begin{abstract}
Although the academic etiquette is daily applied in the world of academia and international conferences, it still remains a largely uncharted territory. Some coded rules emerged with the establishment of first universities in the 12th century; at present, some specific rules are directly stipulated by law, some are governed by university statutes, but many of these rules are customary-law practices. The aim of the present study is to try to define the areas where academic etiquette is applicable and determine their three basic aspects: establishing contact, image and common communication. Detailed attention will be paid to the first aspect dealing primarily with the ways of indicating hierarchy through titles and ranks in the Czech academic world, which currently differs from other Central European countries, although stemming from the same tradition.

This paper was supported by grant SGS-2018-006 Ethics and academic etiquette in international comparison.
\end{abstract}

\section{Keywords}

Academic, Etiquette, Czech Republic, Title, Degree, Habilitation Procedure

\section{Introduction}

Each of the areas of social interaction is governed by a set of more or less coded rules of conduct applicable to the academic community that mainly serve as means of streamlining and 
generally supporting the communication. In general terms, these rules are referred to as good manners, social decency or etiquette. Although the clear rules that were established and originally largely observed in our society are becoming significantly relaxed, the code of the etiquette is still a solid ground that can smoothly navigate us through situations of social interaction. Applicable both do various cultures or societies in the broadest sense of the word. The same applies to the sphere of academia. The following study aims at describing the cornerstones of academic etiquette, with detailed attention on its first part - the hierarchy of Czech academic titles and their use.

\section{Historical Foundation}

The oldest university in the Czech lands is Charles University that was founded on 7 April 1348. Scholars cannot find consensus on some of the historical facts, but according to Šmahel, they mostly agree that: "Charles IV founded the Prague University and attached its privilege to the Bohemian Kingdom“. (Šmahel, 2016, p. 15) However, the University was not only supposed to serve the people of Bohemia, but the entire Central European space. It was not regarded as a Czech institution until 1409, when after the issuance of the Decree of Kutná Hora other university nations departed from the Prague institution leaving it exclusively to the Bohemians. (Stočes, 2010)

The curriculum consisted of liberal arts education (Septem Artes Liberales) divided into trivium: grammar, rhetoric and dialectics, and quadrivium, i.e. arithmetic, geometry, astronomy and music, with trivium being the predominant curriculum set in the Czech lands. Ceremonies and rituals rendered separately at Asian universities were contained in the rhetoric part (spanning the following and other aspects: form and content vs speech act, expression of hierarchy and rituals not only of legal character, Quintilian's association of morals and rhetoric forms). (Kraus, 2011, pp. 53 - 65)

What has changed? Definitely the fact we have no longer a single university. Two types of higher education institutions (proper translation is a college) can be lawfully established in the Czech Republic (Česko, 1998) - of university type - i.e. universities, and of non-university type - i.e. colleges. The college (non-university type institution) offers Bachelor degrees and can also implement Master's programmes as well as the related research activities; colleges do not consist of individual faculties. The university type institution (inaccurately referred to only as university by law) can offer all kinds of study programmes (i.e. also a $\mathrm{PhD}$ programme) as well as the 
related scientific, research, development and innovation, artistic and other creative activities. In addition, a university is composed of several faculties, unlike a college. All universities are colleges, but not all colleges can be called universities. In late 2018, 81 active higher education institutions (of both the university and non-university type) and branches of foreign colleges were active in the Czech Republic. Academic etiquette should be applied in all of them.

\section{Methodology}

"Social conduct - social codex, etiquette - refers to a set of norms, habits, traditions that regulate our behaviour in society and ensure its acceptability in a certain cultural context." (Smejkal \& Bachrachová, 2002, p. 14) Hofstede defines categories of people as certain societies that have their own cultures. (Hofstede \& Hofstede, 1999, p. 14) According to this theory, the categories comprising of students, academic staff, or members of the academic community should be sharing a single culture whose unwritten aspect is academic etiquette. These are norms, habits and traditions generally accepted in the academic environment.

The data used in this paper was obtained primary from legislation (Česko, 1966), (Česko, 1990), (Česko, 1998), and relevant books (Holmerová 2014), (Smejkal \& Bachrachová, 2002), (Nodl et al., 2017). Results can we observing in every day academic life. Classification is created by own analysis.

\section{Parts and Specifics of Academic Etiquette}

If we strive to classify the academic etiquette into specific areas, we can define three basic fields of interest: establishing contact, image and common communication.

The first area covers: indication of hierarchy (titles and superiority) through salutations, use of titles and business cards, greetings and introductions including handshakes.

The area of image includes the first impression made by clothing, haircut, overall appearance and fashion and the use of proxemics in communication (auditorium, rostrum, walking through the room). These include ceremonies (matriculation, graduation) and the related use of insignia (sceptre, chain, robe, standard). It is an expression of the uniqueness of the academic community that is in its written form represented by statutes and guaranteed academic freedoms.

The final area that includes common communication is represented by time management and intellectual property issues, meaning the reconciliation of personal and professional 
activities, practical aspects such as punctuality and also dual - scientific and pedagogical expertise as proposed by Humboldt; hence a greater emphasis on intellectual property issues such as authorship and plagiarism.

This study will further limit its focus to the first area, and especially to the current use of titles and indication of hierarchy at Czech colleges and universities.

\subsection{Application of Basic Rules}

Although in the academic context, the indication of hierarchy does not differ much from the basic rules of etiquette, its application tends to be rather difficult. Therefore, this entire area of concern needs to be described and explained in detail. Based on the rule of social significance, three factors are taken into consideration in the following order: functional superiority, gender and age. A superior is always socially more significant to the subordinate, a woman to a man and an older person to a younger person.

In this case, the functional superiority depends on the internal structure and is not always straightforward. Colleges publish their organisational charts on their website. And they often form a part of the publically available Statutes.

First, there is the academic community (students and academic staff) where the situation is clear: each academic employee is socially more significant to any student. As concerns academic positions, those with the highest academic titles (Professor, Associate Professor) are superior to others. What makes the situation more complicated is the organisational structure composed of self-governing bodies on the one hand, and of management bodies on the other.

The Academic Senate is a self-governing representative academic body composed of elected representatives of the academic community - students and academic staff who elect the chairperson of the Academic Senate both on the level of faculties and on the level of the university. The members of the Academic Senate elect the management, i.e. Deans and the Rector who subsequently nominate their deputies and co-workers (Pro-deans, Pro-rectors, Secretaries and the Questor), who are subsequently in charge of the management bodies. Management bodies are sections, divisions, branches, departments, offices or any other work sections that ensure the operation of the organisation and its parts. Among their employees are IT, library, cash office and building administration staff, HR, administrators, as well as janitors, lawyers and hundreds of others who take care of the function and operation of the university as a whole, such as technical-economic employees (who are not in common contact with students and exceptionally in contact with academic staff). 
At the top of the social hierarchy is the Rector, his or her deputies are Pro-rectors who are equal to the Questor and the Chairperson of the Academic Senate. These are followed by Deans, their deputies Pro-deans, and their equal - the Secretary of the faculty and the Chairperson of the Faculty University Senate. Heads of departments are lower in their rank. Generally speaking, the aforementioned academic staff have higher social standing than technical-economic staff, i.e. even the head of a section at the Rectorate. Based on the definition of universities, or their research and educational mission, each academic employee should be higher in terms of his or her social status than any other employee of the so-called servicing organisations, for example those who are employed at the HR, legal, auditing, marketing or library department or division or staff working at dormitories and cafeterias. Like in the case of general etiquette, discretion has to be used, for instance, a thirty-year-old Department Secretary should not expect to be automatically greeted by a sixty-year-old Professor.

Those with a higher social status have a privilege to know their communication partner as a priority so the socially inferior employees introduce themselves first. Lower-ranking employees are also the first to greet and hand in their business cards.

Socially higher ranking individuals have the privilege to offer a handshake. If they do not do so during greeting, it is inappropriate to enforce the handshake. Therefore, in ceremonies such as graduation, the Dean congratulating the students offers his or her hand first.

Each employee or member of the university staff is socially higher ranking than students, and have to be greeted by the students first when entering the office.

The socially lower-ranking persons, in this case students, also introduce themselves first. In direct contact, the titles are not used during introduction, which should have the following form: Good morning, my name is Petr Novák, not: Good morning, my name is Bachelor Petr Novák. For clarification - greeting (Good morning) is only to be used in direct, i.e. personal communication, during eye contact. Written communication (sent by post or e-mail) should open with a salutation (Dear Doctor). The opening of an e-mail should not say: Good morning/Hello Doctor.

In academic context, the form of the salutation depends primarily on the functional position, while the academic title is of a secondary relevance. If, for example, a student visits doc. PhDr. Jan Wise, Ph.D. in a matter relating to his or her studies in general (for instance prolonging the studies, merit scholarship, request for support for a student organisation, etc.), the Dean should be addressed: Dear Dean Wise. If, however, Mr. Wise is addressed in his role of a 
lecturer in relation to a completed university course, the correct version would be: Dear Associate Professor Wise. Spectabilis (far-famed) is a salutation reserved for academic ceremonies and used as part of matriculation and graduation vows or speeches.

As far as academic titles are concerned, the Czech academic environment has a wider range than applied abroad; therefore, these titles can be classified as follows: non-academic (professional) titles, academic titles, scientific ranks, scientific-pedagogical ranks and honorary ranks.

\subsection{Non-Academic Titles}

Non-academic titles are written after the name separated by a comma and they are not used in a salutation. The title DiS. - certified specialist - can be obtained after graduating from ISCED 6 vocational colleges (UNESCO, 2006) or ISCED 5 conservatories. This group also includes professional titles applied abroad such as BBA - Bachelor of Business Administration, MBA - Master of Business Administration, LL.M. - Legum Magister, Master of Laws, MPH Master of Public Health and MSc - Master of Science.

\subsection{Academic Titles}

Academic titles can be obtained by gaining a degree from either the Bachelor study programme (ISCED 6), Bc. (Bachelor) or BcA. (Bachelor of Arts). These titles precede the personal name and both genders are addressed in the same way - Mr. Bachelor, Mrs. Bachelor. Although the speaker knows that the woman who carries the title is an unmarried woman, the salutation uses the address "Mrs." However, the Bc. title is often not used in salutations and academic staff mostly prefer the word colleague when addressing a student in the Masters programme. This is to indicate a certain sense of connectedness in the academic community and to avoid the need to accurately specify the titles. However, if an academic employee addresses a student as a "colleague", this is not to say that the student is considered absolutely equal or that the student may do the same; they are still expected to be addressed as Doctor, Associate Professor, etc.

The second level of academic titles are those obtained after graduating in Masters Programmes (ISCED 7), both through a subsequent study, or directly five- or six-year Masters programmes (in the legal, pedagogical or medical field). The following titles can be obtained: Mgr., MgA., Ing., Ing. arch., MUDr., MDDr., MVDr.; they always precede the personal name, and they are used in salutations and in the case that they obtain the title in the same study programme, this title replaces the former one. 
Example: Petr Nový graduated from a Bachelor programme in History and completed his Master's degree in the History of Europe, both falling under the History study programme. His correct name and title will be Mgr. Petr Nový. Jan Veselý gained a Bachelor's degree from History (History study programme) and followed on to complete a Master's degree in Economy. The correct form is Ing., Bc. Jan Veselý because the earlier obtained title comes closer to the name. The correct salutation is either Mr. Magister or Mr. Engineer, because we only use the highest title, not all of the degrees that have been gained.

The salutation, Mr. Magister, is used for both the Mgr. and MgA. degree titles, Mr. Engineer in turn goes for the titles of both Ing. and Ing. arch.

The obtained titles do not need to be indicated (in any case, the graduate can only use Ing. Jan Veselý) if their holders do not want to do so. However, it is against the rules of the etiquette and unlawful to use a degree title which has not been obtained.

The degree titles of MUDr. (general medicine doctors), MDDr. (dental and oral medicine doctors) and MVDr. (veterinary medicine doctors) are preceding the personal name and used in the salutation, "Mr. Doctor, Mrs. Doctor". They are commonly referred to as "small doctorate degrees" the obtainment of which is not only subject to a state exam, but also to a defence of $\mathrm{PhD}$.

A small doctorate can be received in other fields; however not to conclude a study, but as a separate, rigorous procedure. Having gained the Mgr., MgA., Ing. or Ing. arch. degrees, the graduate can ask to pass the rigorous examination and to present a dissertation. Those who have passed the examination and defended their dissertation thesis can be awarded the following titles: JUDr. - doctorate in law, PhDr. - doctorate in philosophy applicable in humanities, pedagogical and social sciences (PaedDr. - doctor of pedagogical sciences - was originally awarded), RNDr. - doctorate in natural sciences, PharmDr. - doctorate in pharmacy and two titles in the field of theology: ThLic. - licentiate of theology and ThDr. - doctorate in theology. (Česko, 1998, No. $\S 46$ Section 5a to 5e). Small doctorate replaces the Masters or Engineer title and is written before the name, and the salutation has the form: "Mr. Doctor", "Mrs. Doctor". It is not advisable to include these titles on foreign language versions of business cards, because this type of titles is not known and an unusual title could make the communication too complicated from the very beginning.

The last academic title is Ph.D.- "doctor" awarded to the graduate after the completion of the doctoral degree (ISCED 8). Formerly, this degree included the title, Th.D., relating to the 
study of Theology, and Ph.D. for all other fields of knowledge. The degree title precedes the name and is used in salutation as the only written title. Example: Mgr. Jana Dobrá, Ph.D. - Mrs. Doctor. The academic title, Ph.D., has replaced the former Czech and Slovak scientific degree "Candidate of Sciences" abbreviated as CSc. This title is no longer awarded after 2001, yet it is still valid and added after the personal name, but unlike in the case of Ph.D., it is not used in salutations. A degree higher than CSc. was the "Doctor of Sciences" abbreviated as "DrSc." that replaced CSc. after a successful procedure, but also only until 2001. This was not a college degree, it was exclusively awarded by the Academy of Sciences of the Czech Republic that in 2002 switched to the scientific title DSc. - Research Professor (written after the personal name) that represents "a title awarding exceptionally high qualifications attested by important and original scientific works crucial for the research development in a certain field of science and characterising an outstanding scientific personality". (Academy of Sciences of Czech Republic, 2018) In English, the degree is referred to as Research Professor.

\subsection{Scientific-Pedagogical Ranks}

Scientific-pedagogical ranks include “doc.” (Associate Professor) and "prof." (Professor). The situation becomes a little complicated when it comes to these titles.

The current amendment to the Law on Higher Education describes Associate Professors and Professors as academic staff (Section 70), as well as the process of awarding the Associate Professor title (Section 71 - Appointment of Professors and Section 72 Habilitation Procedure) and also the fact that the Ministry keeps a register of Associate Professors (Section 87 (1) (j) (3) and Section 87b). However, it does not mention any title or scientific-pedagogical degree of Associate Professor (doc.), as well as Professor (prof.).

The procedure for obtaining the "Associate Professor" or "Professor" titles is last mentioned in Section 13 (2) “The 'Professor' title in candidates who have gained the Associate Professor degree in a scientific-pedagogical field or in an art-pedagogical field pursuant to regulations previously in force not having undergone the habilitation procedure, is subject to a habilitation as stipulated herein, without obtaining the Associate Professor title." (Česko, 1990)

Nevertheless, this Decree does not describe the possibility of gaining a title or degree. The issuance and provision of an appointment letter as per Section 6 (5) is subject to a successful habilitation procedure: "The letter of appointment is handed over to the newly appointed degree holder by the Rector of the university; it specifies the name and surname, field of study in which the degree has been awarded, the name of the university or college and the faculty that conducted 
the habilitation procedure, the name of the habilitation thesis, the name and surname of the chairperson and members of the habilitation committee and the opponents and the date as of which the appointment comes into force.” (Česko, 1990)

Act No. 137/2016 Coll. Section II of Act amending the Law on Higher Education and on amending and supplementing related legislation (Higher Education Law), as amended, and some other laws, stipulates: “Titles 'Associate Professor' and 'Professor' obtained in the Slovak Republic between 1 January 1993 and before the expiration of the Agreement between the Governments of the Czech Republic and the Slovak Republic on Mutual Recognition of Educational Documents issued in the Czech Republic and Slovak Republic concluded in Prague on 23 March 2001 shall be regarded as equivalent to the titles 'Associate Professor' and 'Professor' obtained in the Czech Republic during the time period concerned." The only legislative regulation specifying “Associate Professor" as a title, is the Act No. 19/1966 Coll. on Higher Education, annulled already in 1980 whose Section 24 (1) and (2) provides that: "(1) The terms 'Full Professor', "Extraordinary Professor" and "Associate Professor" is a scientificpedagogical title and an art-pedagogical title in artistic fields. (2) Scientific-pedagogical or artpedagogical title is gained based on appointment;..." (Česko, 1966)

The online language handbook of the Czech Language Institute of the Academy of Sciences of the Czech Republic states that: "Abbreviated scientific titles of university pedagogues precede the personal name: doc. (Associate Professor), prof. (Professor). We recommend writing these abbreviations (unless they open a sentence) with minor letters, also on business cards and door name plates.” (Czech Language Institute, 2018).

Although the use of abbreviations for scientific-pedagogical titles such as doc. (Associate Professor) and prof. are not properly anchored in the modern law, we cannot be certain whether they represent a title or a rank, academic etiquette says that they are used as superior to other titles and ranks. We add them to the preceding academic titles and use them in salutations: Mr. Associate Professor, Mr. Professor, Mrs. Associate Professor, Mrs. Professor keeping in mind to drop the doc. (Associate Professor) title if the Professor title has been awarded. Example: doc. PhDr. Ema Velká, CSc. - Mrs. Associate Professor, prof. Mgr. Petr Zima, Ph.D. - Mr. Professor.

Unlike in the case of some other countries, university ranks of Associate Professor and Professor are lifetime qualifications, not a profession. Therefore, Associate Professors have to be addressed as such even if working as Research Assistants and, at the same time, the salutation Professor is used at grammar schools for functional purposes even for Master's degree graduates 
and has nothing to do with the scientific-pedagogical rank of Professor. It is anchored in the Higher Education Law from 1966, the Section 14 (3) of which stipulates: "All college and university graduates are entitled to use, if teaching at secondary schools, the working title "secondary-school professor"." (Česko, 1966)

\subsection{Honorary Degree}

In addition to the aforementioned ranks and degrees, there is a degree that is awarded in the academic community, i.e. honorary degree. The Latin abbreviation is dr. h. c. - doctor honoris causa, meaning honorary doctorate degree; if multiple titles have been awarded, the term multiplex is added: dr. h. c. mult. The title is written with spaces after each dot and after a personal name. It is not used in salutations. Example: prof. Ing. Václav Klaus, CSc., dr. h. c. mult. - the salutation has the following form: Mr. Professor. Such titles can be obtained neither through studies nor by expert thesis or examination, but they are granted by universities to outstanding persons based on the institution's own discretion, most often for their contribution to the field or their lifetime work. It indicates a certain link between the holder of the title and the institution that has given out the award, or the degree of popularity of the person concerned. Former president Václav Klaus has been given 47 of these titles, former president Václav Havel collected 46 of them.

\section{Discussion and Conclusion}

Rules of social conduct ensure good communication flow in a certain community. Like other communities, the academic community has its specifics that are dependent on their history and also their culture. The aim of this study was to introduce the first part of Czech academic etiquette by establishing contact and direct indication of hierarchy through the use of titles and degrees different from other Central European countries.

Research limitation of this paper is maximum number of pages accepted for a paper, so scope of future research is in next two basic field of academic etiquette - image and common communication. Even in this area we expect to find significant differences from the common European standard.

\section{References}

Academy of Sciences of Czech Republic. (2018). Research Title DSc., Retrieved from http://www.avcr.cz/cs/veda-a-vyzkum/vedecky-titul-dsc./index.html

Česko. (1998). Act No. 111/1998 Coll. on Higher Education. 
Česko. (1990). Decree 447/1990 Coll. Decree of the Czech Ministry of Education, Youth and Sports on the habilitation of Associate Professors and the conditions and procedure for the appointment of professors, published in the Collection of Laws, Chapter 75/1990, annulled as of January 1, 1999 by Act No. 111/1998.

Česko. (1966). Act No. 19/1966 Coll. on Higher Education.

Czech Language Institute. (2018). Academy of Sciences of Czech Republic, Online Language Handbook. Retrieved from http://prirucka.ujc.cas.cz/?id=782\#nadpis3

Hofstede, G., \& Hofstede, G. (1999). Kultury a organizace. Software lidské mysli. Praha: Univerzita Karlova.

Holmerová, I. (2014). Minimum akademického bontonu. Praha: Grada Publishing, a. s. .

Kraus, J. (2011). Rétorika v evproské kultuře i ve světě (2. přepracované vydání. vyd.). Praha: Univerzita Karlova v Praze.

Nodl, M., Coufal, D., Možejko, B., Knapek, E., Soukup, P., Bracha, K., a další. (2017). Středověká univerzitní vzdělanost. (M. Nodl, Editor) Praha: Filosofia.

Smejkal, V., \& Bachrachová, H. (2002). Lexikon společenského chování. Praha: Grada Publishing, a. s..

Stočes, J. (2010). Pražské univerzitní národy do roku 1409. Praha: Karolinum.

Šmahel, F. (2016). Alma mater pragensis - Studie k počátkům Univerzity Karlovy. Praha: Nakladatelství Karolinum.

UNESCO. (2006). International Standard Classification of Education: ISCED 1997. Retrieved from http://www.uis.unesco.org/Library/Documents/isced97-en.pdf 